УДК 658.51(075)

\author{
АНАЛИЗ ЭТАПОВ РАЗВИТИЯ ТЕХНИЧЕСКОГО \\ РЕГУЛИРОВАНИЯ В РОССИЙСКОЙ ФЕДЕРАЦИИ
}

\title{
DEVELOPMENT STAGES ANALYSIS OF TECHNICAL REGULATION IN RUSSIAN FEDERATION
}

А.В. Федосов, А.В. Чуркина, Д.Ю. Валекжанин, Р.А. Курылев

Уфимский государственный нефтяной технический университет, г. Уфа, Российская Федерация
Artem V. Fedosov, Alena V. Churkina, Dmitriy Yu. Velekzhanin, Roman A. Kurylev

Ufa State Petroleum Technological University, Ufa, Russian Federation

\section{e-mail: alena-churkina@mail.ru}

Аннотация. Целью данной статьи является анализ процесса развития технического регулирования. Техническое регулирование подразделяется на два основных этапа, первый был до 1991 г., а следующий относится уже к постсоветской Российской Федерации. Для современной модели технического регулирования, на которую переходила страна, требовалось изучение спроса на стандарты и прогнозирование рынка. Без этой оценки реальной картины невозможно было перейти от системы национальной стандартизации государственного устройства к функционированию в современных рыночных условиях. Единая информационная система России включает в себя стандарты и федеральные информационные фонды, которые необходимы для выполнения задач технического регулирования. Отличием международной практики от отечественной был статус стандартов. В России он был обязательным, а во многих странах носил добровольный характер. Федеральным законом «О техническом 
регулировании» были введены дополнительные новые документы, которые решили эту проблему. Деятельность по техническому регулированию направлена на повышение конкурентоспособности продукции на внешнем и внутреннем рынке, а также на обеспечение безопасности процессов и продукции для человека. Механизмы технического регулирования в России гарантируют своевременный обмен информацией, чтобы современные технологии продолжали обеспечивать наилучшую поддержку в области технического регулирования. В результате проведенного анализа выявлены подходы и меры, направленные на усовершенствование технического регулирования в России.

Abstract. The purpose of this article is to analyze the development process of technical regulation. Technical regulation is divided into two main stages, the first was before 1991, and the next one relates to the post-Soviet Russian Federation. For the modern model of technical regulation, which the country switched to, it was necessary to study the demand for standards and market forecasting. Without this assessment of the real picture, it was impossible to move from the system of national standardization of the state system to functioning in modern market conditions. The Unified Information System of Russia includes standards and federal information funds that are necessary for the performance of technical regulation tasks. The difference of international practice from domestic was the standards status. In Russia, it was mandatory, and in many countries it was voluntary. The Federal Law «On Technical Regulation» introduced additional new documents that solved this problem. Technical regulation activities are aimed at improving the products competitiveness in the foreign and domestic markets, as well as ensuring the safety of processes and products for humans. The technical regulation mechanisms in Russia guarantee the timely information exchange so that modern technologies continue to provide the best support in the technical 
regulation field. As the analysis result, approaches and measures aimed at improving technical regulation in Russia were identified.

Ключевые слова: техническое регулирование, стандартизация, безопасность, стандарт, законодательство, закон, регламент, охрана труда, технический регламент, система

Key words: technical regulation, standardization, safety, standard, legislation, law, regulation, labor protection, technical regulation, system

Техническое регулирование зародилось ещё в Древнем Египте: при строительстве применяли кирпичи стандартного размера. Чиновникижрецы контролировали, чтобы кирпич соответствовал размерам. Размеры луков и стрел в армии Древнего Египта были унифицированы.

Техническое регулирование диаметров колес повозок является одним из первых актов, которые издал первый император Китайской империи и династии Хань Лю Баня, пришедший к власти в 206 г. до н.э.

В средневековой Венеции были стандартизированы паруса, весла и мачты флота. Стандартные детали, такие как боевые галеры, хранились в арсенале. Благодаря этому галеры? пострадавшие в бою, можно было качественно и легко отремонтировать или заменить на новые.

Техническое регулирование присутствовало и в живой среде, так в процессе эволюции создавались и развивались многие виды растений и животных. Пчелиные соты, плотины бобров и гнезда ласточек являются примерами стандартов, созданных самой природой $[1,2]$.

При Иване Грозном появились первые сведения о техническом регулирование в России. Он издал указ об установлении постоянных размеров пушечных ядер, а также были введены калибры для контроля этих размеров.

Во времена правления Петра I был выпущен ряд указов, которые предписывали делать изделия военной техники по точным образцам. 
Одним из направлений регулирования был выпуск общегосударственных единых монет. Это укрепляло порядок в стране, и монеты являлись мерами веса. В 1875 г. в Париже 17 государств приняли участие в конвекции по принятию метра в виде единицы измерения длины.

В конце XIX в. развитие промышленности, техники и концентрации производства были получены большие успехи. Поэтому в странах с более развитой экономической системой стремились к организованной системе технического регулирования. Так, образовывались национальные организации по стандартизации, например в Англии был образован Комитет стандартов.

В начале XX в. милитаризация большинства стран требовала создания большого количества вооружения, при этом должен был выполняться принцип взаимозаменяемости, а это можно было решить только с использованием технического регулирования.

Развитие технического регулирования в СССР проходило последовательно. Совнарком в 1918 г. принял Декрет о введении Международной метрической системы мер и весов, который является первым государственным актом. С него положено начало технического регулирования в СССР.

Важнейшей государственной задачей в первые годы Советской власти стала индустриализация, которая требовала решения экономических и технических вопросов. Для решения экономических и технических вопросов, касающихся выпускаемого оборудования и продукции, необходимо было установить нормы, единые технические требования и характеристики. В связи с этим был создан Комитет по стандартизации при Совете труда и обороны.

В СССР были утверждены общесоюзные стандарты, в числе первых были технические документы на номенклатуру сортов пшеницы, чугуна, сортамент проката металлов, а также ряд продуктов и товаров народного потребления. 
Во время Великой Отечественной войны техническое регулирование и метрология имели высокий уровень в оборонной промышленности, тем самым позволяли организовывать серийное производство военной техники и оружия, что внесло свой вклад в достижение победы.

В 1968 г. были утверждены различные стандарты, установившие государственную систему стандартов СССР, такие как Единая система конструкторской документации, Единая система технологической подготовки производства и другие.

Директивные документы по вопросам развития народного хозяйства явились основными этапами развития технического регулирования СССР. Так, было предусмотрено улучшение планирования технического регулирования, создание комплексной системы регулирования, поставлена задача по обеспечению высокого уровня научно-технических стандартов и их регулярного обновления.

Были утверждены головные организации для проведения испытаний главных видов продукции культурно-бытового и производственнотехнического назначения. Проводилось усиление контроля за качеством выпускаемой продукции, а также за правильностью проведения ее аттестации [3-5].

Во время перестройки государственного устройства и изменения административно-командной системы проведено также реформирование технического регулирования. Стержнем для новой системы технического регулирования явилось все то, что складывалось в течение 80 лет образования стандартизации.

Со временем люди стали меньше доверять государству, возникла необходимость передачи некоторых функций органов государственной власти в независимые частные организации, тем самым вовлекли общество в государственное управление.

Деятельность органов государственной власти стала более прозрачной, соответственно, повысилось и качество оказываемых услуг, а также 
увеличилось доверие жителей к государственной политике и к государству в целом.

Основным направлением в реформировании технического регулирования были стимулирование и поддержка разработки применения национальных стандартов. После прохождения всех процедур по стандартизации и соблюдения всех требований предприятие могло получить право на маркировку своей продукции знаком соответствия государственным стандартам, тем самым оно получало преимущество на мировом и внутреннем рынке $[6,7$.

К началу XXI в. в РФ функционировал орган технического регулирования - Госстандарт России, который являлся федеральным органом исполнительной власти и осуществлял функциональное регулирование и межотраслевую координацию в области стандартизации. Указом Президента Российской Федерации от 22 сентября 1998 г. № 1142 образован Государственный комитет Российской Федерации по стандартизации, метрологии и сертификации с передачей ему функций Министерства промышленности и торговли Российской Федерации по реализации государственной политики в сфере стандартизации, метрологии и сертификации.

Начиная с 1992 г. в России разрабатывают планы государственной стандартизации на год. Они включают в себя пересмотр, разработку и внесение изменений не только в государственные стандарты, но и в международные и межгосударственные. Для современной модели технического регулирования, на которую переходила страна, требовалось изучение спроса на данные стандарты и прогнозирование их рынка. Без этой оценки реальной картины невозможно было перейти от системы национальной стандартизации государственного устройства к функционированию в современных рыночных условиях $[8,9]$.

Федеральный закон № 184 «О техническом регулировании» от 01.07.2003 определял правила разработки стандартов, участников работ и 
взаимосвязь с техническими регламентами. Он является стратегическим, на нем основываются реформы технического нормирования и административные механизмы.

Законодательство требовало нового подхода к вопросам применения и установления обязательных добровольных требований к работам, продуктам и услугам, отвечающим международной политике и рыночной экономике [10-12].

До вступления в силу требований определенных технологических регламентов к продукции, эксплуатации, хранению, реализации, утилизации, перевозкам, процессам производства, указанных в национальных стандартах, обязательному исполнению подлежали только те, которые соответствовали следующим целям:

защита здоровья или жизни граждан, имущество юридических или физических лиц, а также муниципальное и государственное;

охрана здоровья или жизни растений и животных, окружающей среды; информирование, а также предупреждение потребителей о действиях, которые могут ввести их в заблуждение.

Указом Президента Российской Федерации от 9 марта 2004 г. № 314 на базе Госстандарта России была создана Федеральная служба по техническому регулированию и метрологии. В этом же году Указом Президента Российской Федерации от 20 мая № 649 Федеральная служба по техническому регулированию и метрологии преобразована в Федеральное агентство по техническому регулированию и метрологии (Ростехрегулирование).

Если рассматривать техническое регулирование как деятельность по оказанию услуг и выполнению работ, установлению характеристик и правил в сферах обращения и производства продукции, то оно может помочь в достижение определенных целей [13].

Технические стандарты, регламенты, своды правил, процедуры подтверждения соответствия, контроля, надзора и аккредитации являются 
основными элементами технического регулирования. Они существовали и раньше, но теперь они потребовали больших изменений.

Наибольшим отличием между международной и отечественной практикой был статус стандартов. В России он был обязательным, а во многих странах носил добровольный характер. В Федеральном законе «О техническом регулировании» были введены дополнительные новые документы, которые решили эту проблему [14].

Новая система технического регулирования превратилась в двухуровневую систему. Первый уровень включал в себя технические регламенты, которые принимались постановлением правительства или федеральным законом. Второй уровень включал в себя гармонизированные технические регламенты, такие как своды правил и добровольные стандарты. Они помогают определить оптимальный путь для производителя, для реализации обязательных требований технического регламента.

Данная система стандартов не ограничивается формированием доказательной базы технических регламентов. Одной из главных целей так и осталось повышение конкурентоспособности работ, продукции и услуг.

Стандарты в новой системе формируют законодательную базу. Повышение конкурентоспособности услуг, работ и продукции является основной целью регулирования. Техническое регулирование осуществляют также в целях обеспечения жизни и здоровья людей, экологической безопасности [15].

Современная система технического регулирования России уменьшила её ресурсные возможности, но сохранила черты старой государственной системы. Так, сейчас зарегистрировано около 400 технических комитетов по стандартизации. Организационная структура национальной системы основана на международной практике. 
Постановлением Правительства РФ от 09 июня 2010 г. № 408 краткое наименование Федерального агентства «Ростехрегулирование» заменено на «Росстандарт».

Единые позиции и взгляды России на международном уровне обеспечиваются в процессе сотрудничества между потребителями, органами исполнительной власти и промышленностью. Единая информационная система включает в себя стандарты и федеральные информационные фонды, которые необходимы для выполнения задач технического регулирования. Для увеличения эффективности государственных поставок работ, услуг и продукции используют стандарты в конкурсах на закупки для государственных нужд национальные стандарты [9].

Механизмы технического регулирования в России гарантируют своевременный обмен информацией о деятельности и потребностях в области стандартизации, чтобы информационные технологии продолжали обеспечивать наилучшую поддержку в области технического регулирования.

\section{Вывод}

По результатам всего вышеизложенного, можно сделать вывод, что деятельность по техническому регулированию направлена на повышение конкурентоспособности продукции на внешнем и внутреннем рынке за счет осуществления деятельности по подтверждению соответствия и стандартизации, а также на обеспечение безопасности процессов и продукции для человека. 


\section{Список используемых источников}

1. Абдрахманов Н.X. Анализ отечественного и зарубежного опыта исследований в области безопасного проектирования и эксплуатации технологических объектов нефтеперерабатывающих и нефтехимических производств // Экспертиза промышленной безопасности и диагностика опасных производственных объектов: матер. Междунар. науч.-практ. конф. Уфа, 2015. № 5. С. 162-164.

2. Abdrakhmanov N., Abdrakhmanova K., Vorohobko V., Abdrakhmanova L., Basyirova A. Development of Implementation Chart for Non-Stationary Risks Minimization Management Technology Based on Information-Management Safety System // Journal of Engineering and Applied Sciences. 2017. No. 12. pp. 7880-7888.

3. Федосов А.В., Абдрахимова И.Р., Закирова З.А. Перспективы применения риск-ориентированного подхода в области промышленной безопасности // Сетевое издание «Нефтегазовое дело». 2018. № 1. C. 145-161.

4. Kunelbayev M.M., Gaisin E.Sh., Repin V.V., Galiullin M.M., Abdrakhmanova K.N. Heat Absorption by Heat-Transfer Agent in a Flat Plate Solar Collector // International Journal of Pure and Applied Mathematics. 2017. Vol. 115. No. 3. pp. 561-575.

5. Кускильдин Р.А., Абдрахманов Н.Х., Закирова З.А., Ялалова Э.Ф., Абдрахманова К.Н., Ворохобко В.В. Современные технологии для проведения производственного контроля, повышающие уровень промышленной безопасности на объектах нефтегазовой отрасли // Проблемы сбора, подготовки и транспорта нефти и нефтепродуктов. 2017. Вып. 2 (108). С. 111-120.

6. Abdrakhmanov N.Kh., Vadulina N.V., Fedosov A.V., Ryamova S.M., Gaisin E.Sh. A New Approach for a Special Assessment of the Working Conditions at the Production Factors' Impact through Forecasting the Occupational Risks // Man in India. 2017. Vol. 97. No. 20. P. 495-511. 
7. Федосов А.В., Идрисова К.Р., Абдрахманов Н.Х., Ефимова А.В., Градобоева К.В., Расулов С.Р. Теоретические основы промышленной безопасности. Уфа: УГНТУ, 2018. 128 с.

8. .Sekerin V.D., Gaisina L.M., Shutov N.V., Abdrakhmanov N.Kh., Valitova N.E. Improving the Quality of Competence-Oriented Training of Personnel at Industrial Enterprises Quality // Access to Success. 2018. Vol. 19. № 165 . P. 68-73.

9. Абдрахманов Н.Х., Турдыматов А.А., Абдрахманова К.Н., Ворохобко В.В. Обеспечение безопасности технологических трубопроводных систем на предприятиях нефтегазового комплекса // Электронный научный журнал «Нефтегазовое дело». 2015. Т. 13. № 4. C. $254-260$.

10. Абдрахманов Н.Х., Абдрахманова К.Н., Ворохобко В.В., Шайбаков Р.А. Анализ системных рисков при проектировании и эксплуатации опасных производственных объектов // Промышленная безопасность на взрывопожароопасных и химически опасных производственных объектах: матер. VIII науч.-практ. конф. Уфа: УГНТУ, 2014. C. 28-31.

11. Абдрахманов Н.Х., Давлетов В.М., Абдрахманова К.Н., Ворохобко В.В., Абдрахманов Р.Н. Повышение безопасности эксплуатации газопроводов // Нефтегазовое дело. 2016. Т. 14, № 3. C. 183-187.

12. Павлова 3.Х., Азметов Х.А., Абдрахманов Н.Х., Павлова А.Д. Оценка и обеспечение безопасности эксплуатации нефтегазопроводов в условиях нестационарности технологических параметров // Известия Томского политехнического университета. Инжиниринг георесурсов. 2018. T. 329. № 1. C. 132-137. 
13. Fedosov

A.V., Abdrakhmanov N.Kh., Gaysin E.Sh., Sharafutdinova G.M., Abdrakhmanova K.N., Shammatova A.A. The Use of Mathematical Models in the Assessment of the Measurements' Uncertainty for the Purpose of the Industrial Safety Condition Analysis of the Dangerous Production Objects // International Journal of Pure and Applied Mathematics. 2018. Vol. 119. No. 10. Special Issue. P. 433-437.

14. Абдрахманов Н.Х., Шайбаков Р.А., Байбурин Р.А. Роль анализа причин аварий на объектах нефтехимических и нефтеперерабатывающих производств в оценке уровня рисков // Нефтегазовое дело. 2008. Т. 6. № 1. C. 189-190.

15. Fedosov A.V., Khamitova A.N., Abdrakhmanova K.N., Abdrakhmanov N.Kh. Assessment of the Human Factor Influence on the Accident Initiation in the Oil and Gas Industry // Территория Нефтегаз. 2018. № 1-2. C. 14-20.

\section{References}

1. Abdrakhmanov N.Kh. Analiz otechestvennogo i zarubezhnogo opyta issledovanii $\mathrm{V}$ oblasti bezopasnogo proektirovaniya $\mathrm{i}$ ekspluatatsii tekhnologicheskikh ob"ektov neftepererabatyvayushchikh i neftekhimicheskikh proizvodstv [Analysis of Domestic and Foreign Research Experience in The Field of Safe Design and Operation of Technological Facilities of Oil Refining and Petrochemical Industries]. Materialy Mezhdunarodnoi nauchnoprakticheskoi konferentsii «Ekspertiza promyshlennoi bezopasnosti i diagnostika opasnykh proizvodstvennykh ob"ektov» [Materials of The International Scientific and Practical Conference «Examination of Industrial Safety and Diagnostics of Hazardous Production Facilities»]. Ufa, 2015, No. 5, pp. 162-164. [in Russian]. 
2. Abdrakhmanov N., Abdrakhmanova K., Vorohobko V., Abdrakhmanova L., Basyirova A. Development of Implementation Chart for Non-Stationary Risks Minimization Management Technology Based on Information-Management Safety System. Journal of Engineering and Applied Sciences, 2017, No. 12, pp. 7880-7888.

3. Fedosov A.V., Abdrakhimova I.R., Zakirova Z.A. Perspektivy primeneniya risk-orientirovannogo podkhoda $\mathrm{V}$ oblasti promyshlennoi bezopasnosti [Prospects for Risk-Based Approach Usage in Industrial Safety Sphere]. Setevoe izdanie «Neftegazovoe delo»-Online Edition «Oil and Gas Business», 2018, No. 1. pp. 145-161. [in Russian].

4. Kunelbayev M.M., Gaisin E.Sh., Repin V.V., Galiullin M.M., Abdrakhmanova K.N. Heat Absorption by Heat-Transfer Agent in a Flat Plate Solar Collector. International Journal of Pure and Applied Mathematics, 2017, Vol. 115, No. 3, pp. 561-575.

5. Kuskil'din R.A., Abdrakhmanov N.Kh., Zakirova Z.A., Yalalova E.F., Abdrakhmanova K.N., Vorokhobko V.V. Sovremennye tekhnologii dlya provedeniya proizvodstvennogo kontrolya, povyshayushchie uroven' promyshlennoi bezopasnosti na ob"ektakh neftegazovoi otrasli [Modern Technologies for Operation Control Monitoring Increasing Industrial Safety Level on Oil and Gas Industry Objects]. Problemy sbora, podgotovki i transporta nefti $i$ nefteproduktov - Problems of Gathering, Treatment and Transportation of Oil and Oil Products, 2017, Issue 2 (108), pp. 111-120. [in Russian].

6. Abdrakhmanov N.Kh., Vadulina N.V., Fedosov A.V., Ryamova S.M., Gaisin E.Sh. A New Approach for a Special Assessment of the Working Conditions at the Production Factors' Impact through Forecasting the Occupational Risks. Man in India, 2017, Vol. 97, No. 20, pp. 495-511.

7. Fedosov A.V., Idrisova K.R., Abdrakhmanov N.Kh., Efimova A.V., Gradoboeva K.V., Rasulov S.R. Teoreticheskie osnovy promyshlennoi bezopasnosti [Theoretical Bases of Industrial Safety]. Ufa, USPTU Publ., 2018. 128 p. [in Russian]. 
8. Sekerin V.D., Gaisina L.M., Shutov N.V., Abdrakhmanov N.Kh., Valitova N.E. Improving the Quality of Competence-Oriented Training of Personnel at Industrial Enterprises. Access to Success, 2018, Vol. 19, No. 165, pp. 68-73.

9. Abdrakhmanova K.N., Shutov N.V. Obespechenie bezopasnoi ekspluatatsii bloka podgotovki pitatel'noi vody kotlov i vodyanogo para ustanovki proizvodstva vodoroda [Ensuring Safe Operation of Feed Water of Boilers and Water Vapor Block of Hydrogen Production Installation]. Materialy Mezhdunarodnoi nauchno-prakticheskoi konferentsii «Ekspertiza promyshlennoi bezopasnosti i diagnostika opasnykh proizvodstvennykh ob"ektov» [Materials of the International Scientific and Practical Conference «Examination of Industrial Safety and Diagnostics of Hazardous Production Facilities»]. Ufa, 2016. Vol. 7. No. 1. pp. 166-171. [in Russian].

10. Abdrakhmanov N.Kh., Abdrakhmanova K.N., Vorokhobko V.V., Shaibakov R.A. Analiz sistemnykh riskov pri proektirovanii i ekspluatatsii opasnykh proizvodstvennykh ob"ektov [Analysis of System Risks in the Design and Operation of Hazardous Production Facilities]. Materialy VIII nauchnoprakticheskoi konferentsii Promyshlennaya bezopasnost' na vzryvopozharoopasnykh $i$ khimicheski opasnykh proizvodstvennykh ob"ektakh [Materials of The VIII Scientific and Practical Conference Industrial Safety at Explosive and Chemically Hazardous Production Facilities]. Ufa, USPTU Publ., 2014. pp. 28-31. [in Russian].

11. Abdrakhmanov N.Kh., Davletov V.M., Abdrakhmanova K.N., Vorokhobko V.V., Abdrakhmanov R.N. Povyshenie bezopasnosti ekspluatatsii gazoprovodov [Improving the Safety of Gas Pipelines Operation]. Neftegazovoe delo-Petroleum Engineering, 2016, Vol. 14, No. 3, pp. 183-187. [in Russian]. 
12. Pavlova Z.Kh., Azmetov Kh.A., Abdrakhmanov N.Kh., Pavlova A.D. Otsenka i obespechenie bezopasnosti ekspluatatsii neftegazoprovodov v usloviyakh nestatsionarnosti tekhnologicheskikh parametrov [Assessment and Safety of Operation of Oil and Gas Pipelines in Non-Steady Conditions of Technological Parameters]. Izvestiya Tomskogo politekhnicheskogo universiteta. Inzhiniring georesursov - Bulletin of the Tomsk Polytechnic University. Geo Assets Engineering, 2018, Vol. 329, No. 1, pp. 132-137. [in Russian].

13. Fedosov A.V., Abdrakhmanov N.Kh., Gaysin E.Sh., Sharafutdinova G.M., Abdrakhmanova K.N., Shammatova A.A. The Use of Mathematical Models in the Assessment of the Measurements' Uncertainty for the Purpose of the Industrial Safety Condition Analysis of the Dangerous Production Objects. International Journal of Pure and Applied Mathematics, 2018, Vol. 119, No. 10, Special Issue C, pp. 433-437.

14. Abdrakhmanov N.Kh., Shaibakov R.A., Baiburin R.A. Rol' analiza prichin avarii na ob"ektakh neftekhimicheskikh i neftepererabatyvayushchikh proizvodstv $\mathrm{v}$ otsenke urovnya riskov [The Role of Analysis of the Causes of Accidents at Petrochemical and Oil Refining Facilities in Assessing the Level of Risks]. Neftegazovoe delo - Petroleum Engineering, 2008, Vol. 6, No. 1. pp. 189-190. [in Russian].

15. Fedosov A.V., Khamitova A.N., Abdrakhmanova K.N., Abdrakhmanov N.Kh. Assessment of the Human Factor Influence on the Accident Initiation in the Oil and Gas Industry. Territoriya Neftegaz - Oil and Gas Territory, 2018, No. 1-2, pp. 14-20. 


\section{Сведения об авторах}

\section{About the authors}

Федосов Артем Васильевич, канд. техн. наук, доцент, доцент кафедры «Промышленная безопасность и охрана труда», УГНТУ, г. Уфа, Российская Федерация

Artem V. Fedosov, Candidate of Engineering Sciences, Associated Professor, Assistant Professor of Industrial Safety and Labor Protection Department, USPTU, Ufa, Russian Federation

e-mail: fedsv-artem@ rambler.ru

Чуркина Алена Викторовна, студент кафедры «Промышленная безопасность и охрана труда», УГНТУ, г. Уфа, Российская Федерация

Alena V. Churkina, Student of Industrial Safety and Labor Protection Department, USPTU, Ufa, Russian Federation

e-mail: alena-churkina@mail.ru

Валекжанин Дмитрий Юрьевич, канд. техн. наук, доцент кафедры «Промышленная безопасность и охрана труда», УГНТУ, г. Уфа, Российская Федерация

Dmitriy Yu. Velekzhanin, Candidate of Engineering Sciences, Assistant Professor of Industrial Safety and Labor Protection Department, USPTU, Ufa, Russian Federation

e-mail: unimix@mail.ru

Курылев Роман Александрович, студент кафедры «Промышленная безопасность и охрана труда», УГНТУ, г. Уфа, Российская Федерация

Roman A. Kurylev, Student of Industrial Safety and Labor Protection Department, USPTU, Ufa, Russian Federation

e-mail: romkury@yandex.r 